\title{
EL ACCESO DE LOS PARTICULARES A LA JURISDICCIÓN COMUNITARIA
}

\author{
Carolina Dackö* \\ Paula Daniela Egües \\ Matias Isás ${ }^{*+2}$
}

SUMÁRIO: I1. Introdução. Os passos para um Direito Comunitário Próprio, integrado aos ordenamentos jurídicos nacionais. 3. O Sistema de Aplicaçăo de Direito Comunitário. 4. Resumo. 5. Caso. 6. MERCOSUL: Efeito Direto, Primazia, Efeito Imediato. 7. Ius Inter Iura: a Relação entre o Direito Argentino e o Ordenamento Juridico do MERCOSUL. 8. Caso.9. Conclusão. 10. Bibliografía.

SUMMARY: 1. Introduction. The steps for a Right Comunitario Own, Integrated to the national norms. 3. The Right Application System Comunitario. 4. Summary. 5. Case 6. MERCOSUL: Straight Effect, Primacy, Immediate Effect. 7. Ius Inter Iura: the Relation between the Right Argentine and the norms of the MERCOSUL. 8. Case 9. Conclusion. 10. Bibliography.

SUMARIO: 1.Introducción. 2. Los Pasos Hacia Un Derecho Comunitario Propio, Integrado En Los Ordenes Judiciales Nacionales. 3. El Sistema De Aplicación De Derecho Comuntario. 4.Resumen. 5. Caso. 6. MERCOSUR: Efecto Directo, Primacia, Efecto Inmediato. 7. Ius Inter Iura: La Relación Entre El Derecho Argentino Y El Ordenamiento Juridico Del Mercosur.8. Caso. 9. Conclusion. 10. Bibliografia.

RESUMO: Em seguidá é apresentada uma monografia da investigação, cujo o alvo principal é fazer uma análise comparativa dos efeitos próprios de um sistema de integração; entre a Comunidade Européia e o MERCOSUL. Assim como, tentaremos demonstrar como um individuo, ante um conflito concreto, consente à jurisdição comunitária, tanto quanto em um sistema quanto no outro.

ABSTRACT: It is presented an investigation monography, whose main objective is to make a comparative analysis of the integration system effects;

\footnotetext{
* Matstra en Derecho International y Europeo, del Unversidad de Ciencias Sociales de Toulouse Francia, Estudiande de Master Progranme of Law, Universidad de Gothenbora Suecia. Pasante en la Commision Enropea, Dirección di Impuestos y Union Adnanera. $\because$ Alumnos de la carrera de Derecho de la Universidad Austral, Argentina.
} 
between European Communty and MERCOSUR. As well, we will try to demonstrate how an individual in face of a concrete conflict appeals to the communitarian jurisdiction, in both systems.

RESUMEN: A continuación se presenta una monografia de investigación, cuyo objetivo fundamental es realizar un análisis comparativo de los efectos propios de un sistema de integración; entre la Comunidad Europea y el MERCOSUR. A su vez, intentaremos demostrar cómo un particular ante un conflicto concreto accede a la jurisdicción comunitaria, tanto cn un sistema como en el otro.

PALAVRAS-CHAVES: Comunidade Européa. MERCOSUI. Acesso. JH risdiçóo. Particulares.

KEY-WORDS: European Community. MERCOSUR Access. Jurisdición. Individuals.

PALABRAS-LLAVES: Comunidad Europea. MERCOSUR. Acceso. Jurisdición. Particulares.

\section{Introducción}

Tratando el tema de integración en la comunidad europea, fueron las personas físicas y jurídicas quienes impulsaron la integración económica. La integración material fue avanzando por la voluntad de los particulares de conducir al comercio intra europeo. Así reclamaron contra las barreras estatales que infringían aquel comercio.

Como aquellas personas son consideradas sujetos judiciales en el orden jurídico comunitario, y la jurisprudencia del TJCE ha establecido que el derecho comunitario tiene un efecto directo, resulta que los particulares pueden recurrir al derecho comunitario por vía de un procedimiento en el ámbito nacional.

Gracias a este mecanismo, los derechos de los particulares fundados en los Tratados, han sido implementados eficazmente en los ordenes internos nacionales.

Por lo tanto cuando los particulares pueden ver que sus derechos comunitarios son verdaderos y que pueden alcanzarlos fácilmente, el derecho comunitario tiene una función social en los países integrantes de la comunidad europea. 


\section{Los Pasos Hacia un Derecho Comunitario Proprio, Integra- do en los Ordenes Judiciales Nacionales}

En esta parte intentamos presentar brevemente los fallos que han sido determinantes para el nacimiento de un derecho comunitario. Luego trataremos de explicar el mecanismo que permite la aplicación directa del derecho comunitario por los jueces nacionales.

A lo largo del desarrollo del derecho comunitario, lo fundamental y necesario fue recortar las competencias de los ordenes estatales e incluirlos en un nivel comunitario.

En el fallo de Van Gend en Loos, de 1963, el TJCE establece que;

"La Comunidad Económica Europea constituye un nuevo ordenamiento jurídico de Derecho internacional, a favor del cual los Estados miembros han limitado su soberanía, si bien en ámbitos restringidos, y cuyos sujetos son, no sólo los Estados miembros, sino también sus nacionales."

En resumen se declara en el fallo que el derecho elaborado por la comunidad es un orden propio que debe quedar paralelamente al lado de cada orden judicial estatal, o sea, que el derecho comunitario tiene un efecto directo. Sin embargo, antes de explicar en detalle este término, seguiremos con una breve presentación del orden judicial comunitario.

\section{2.a. Orden Comunitario; derecho originario y derecho derivado}

Para entender el orden comunitario europeo, es imprescindible esclarecer que en este orden existen normas de dos categorías. Primero son las normas de derecho originario y luego las de derecho derivado.

Las normas del derecho originario emanan de los Tratados, por ejemplo; principio de no discriminación, principio de libre circulación dentro del mercado interno, las disposiciones que reglan la distribución y delimitación de competencia de las instituciones comunitarias.

Las normas del derecho derivado son los actos pronunciados por las instituciones comunitarias.

Entre el derecho originario y derecho derivado, el primero es el que tiene primacía. Los Tratados construyen la comunidad y las reglas de derecho primario no pueden ser derogadas por un acto de una institución. 


\section{2.b. El efecto directo del derecho originario y derivado}

En el fallo ya mencionado, Van Gend, el efecto directo fue atribuido al derecho originario.

En una segunda etapa el TCJE extendió el efecto directo a ciertas normas de derecho derivado. La competencia de producir el derecho derivado esta distribuida entre las instituciones de la comunidad. Así existen varios tipos de normas de derecho derivado. Seguimos con una presentación de aquellas.

En el artículo 249 del Tratado de la Comunidad, están listados las disposiciones que pueden tomar las instituciones de la CE;

"Para el cumplimiento de su misión, el Parlamento Europeo y el Consejo conjuntamente, el Consejo y la Comisión adoptarán reglamentos y directivas, tomarán decisiones y formularán recomendaciones o emitirán dictámenes, en las condiciones previstas en el presente Tratado.

El reglamento tendrá en alcance general. Será obligatorio en todos sus elementos y directamente aplicable en cada Estado miembro.

La directiva obligará al Estado miembro destinatario en cuanto al resultado que deba conseguirse, dejando, sin embargo, a las autoridades nacionales la elección de la forma y de los medios.

La decisión será obligatoria en todos sus elementos para todos sus destinatarios.

Las recomendaciones y los dictámenes no serán vinculantes."

El efecto directo atribuido a aquellas normas depende de qué relación de sujetos se habla. Si es una relación entre el Estado Miembro y un particular, se trata de una relación vertical. En la situación que implica una relación entre dos particulares (sean personas fisicas o jurídicas), se habla de una relación horizontal.

Con respecto a la soberanía de los Estados Miembros y sus ordenes judiciales nacionales, no se puede exigir que todas las normas comunitarias tengan un efecto directo en su totalidad. Por ello, distinguimos entre el efecto directo horizontal y el efecto directo vertical.

Volvamos a mirar la lista del articulo 249; 


\section{2.b.i. Los Reglamentos}

En cuanto a los reglamentos, ellos tienen un efecto directo, tanto vertical como horizontal ${ }^{2}$ El TJCE ha llegado a esta condusión al cabo de la argumentación siguiente;

-un reglamento tiene el efecto inmediato, como tal confiere derechos a los particulares que los Estados Miembros son obligados a proteger dentro del orden interno, lo cual da el efecto directo del reglamento

-un reglamento puede conferir derechos, así como imponer obligaciones a los particulares, lo cual implica el efecto directo horizontal, o sea, un particular puede impugnar una obligación comunitaria contra otro particular.

\section{2.b.ii. Las Directivas}

Normalmente el contenido de las directivas son "instrucciones" de acción destinada a los Estado Miembros. Son reglas que los Estados Miembros tienen que implementar en sus ordenes internos para armonizar sus legislaciones.

Así son obligaciones a los Estados Miembros, sin implicación de los particulares. Sin embargo, en el fallo Van Duyn ${ }^{3}$ el TJCE estableció, que aún las directivas y las decisiones tienen en ciertas circunstancias efecto directo.

Según la jurisprudencia si las condiciones siguientes son reunidas, la directiva tiene efecto directo vertical; Que la directiva:

1. sea beneficiosa para los particulares;

2. el contenido sea claramente establecido en la directiva y,

3. la fecha de implementación en el orden nacional se haya vencido.

Ello implica que un particular puede invocar la directiva en un procedimiento nacional cuando su contraparte sea un Estado Miembro.

En varios fallos, el TJCE ha negado la facultad de una directiva para tener efecto directo horizontal. Por lo tanto, el Estado tiene la obligación de implementar las reglas contenidas en dicha norma comunitaria. En consecuencia, un particular no puede quedar vinculado por una regla originada en una directiva comunitaria que no exista en el orden nacional. Sin embargo en el momento que el Estado Miembro haya implementado el contenido de la directiva en el orden nacional, el particular estará, no obstante, vinculado por una regla de derecho interno.

"Commenaire Megret, Droit de la CEE no. 10, La Cour de Justice Les Actes des Institutions, Edirions de L.: Univerité de Bruxelles p. 492

'TJCE, sentencia del 4 de diciembre de 1974, Van Duyn, as. 41/74, Rec. 1974. 
Así que en un procedimiento nacional entre dos particulares, ninguno de ellos puede invocar una norma derivada de una directiva que no ha sido implementado en el orden nacional.

Se puede considerar limitado en su aplicación, que las directivas sólo tienen efecto directo horizontal. Sin embargo el TJCE ha ampliado la aplicación de las directivas. En el fallo de British $\mathrm{Gas}^{4}$, se trataba de dos particulares, un cliente de British Gas y la empresa misma. En este caso la empresa había sido privatizada hacía poco tiempo. Antes era una empresa estatal y como no había cambiado demasiado la estructura de la empresa, el TJCE consideraba que era un representante del estado, por lo tanto la relación era vertical y el cliente podía invocar las reglas en una directiva. Eso ilustra la progresividad y pragmatismo del TJCE.

\section{2.b.iii. Las Decisiones}

Normalmente las decisiones tomadas por la comunidad europea tienen un destinatario especifico con instrucciones especificas. Así que tiene efecto directo vertical pero no horizontal. En un procedimiento nacional un particular no puede invocar que la contraparte no haya concluido con una decisión destinada a él.

La decisión es una norma diferente a las otras normas de derecho derivado porque está dirigida a un particular. Por eso el particular tiene el derecho de reclamar una decisión directamente frente al TJCE según el cuarto párrafo del art. 230;

"Toda persona física o jurídica podrá interponer, en las mismas condiciones, recurso contra las decisiones de las que sea destinataria y contra las decisiones que, aunque revistan la forma de un reglamento o de una decisión dirigida o otra persona, le afecten directa e individualmente."

\section{2.b.iv Las recomendaciones y dictámenes}

Como esta declarado en el artículo, no son vinculantes, así no tienen efecto directo en el orden nacional. 


\section{Bb. Principio de la interpretación conforme:}

Cuando una norma comunitaria no ha sido implementada y no tiene efecto directo, la protección del derecho del particular es bastante débil. La jurisprudencia del TJCE ha intentado solucionar este problema por vía del Principio de interpretación conforme. Es en el fallo Faccio Dori donde se estableció que el juez nacional tiene que aplicar una regla local que tiene su origen en el derecho comunitario, estando obligado a interpretarla lo más semejante posible a éste. No puede modificar la regla nacional pero tiene una obligación de interpretarla en favor del derecho comunitario.

\section{2.c. La Primacía del Derecho Comunitario}

De lo que hemos visto del efecto directo, no tendría vigencia si el TJCE no hubiera elaborado la teoría de la primacía del derecho comunitario sobre el derecho nacional.

En el caso Costa c/ ENEL ${ }^{6}$, se declaró por primera vez la primacía (si bien la primera referencia a este principio fue hecha en forma tangencial en la sentencia Humlet as.6/60). En este fallo un juez italiano debía aplicar una ley nacional que había sido instituida después de la entrada en vigor del Tratado de Roma en orden judicial italiana. El principio de "ley posterior deroga ley anterior" dio razón a proceder a esta operación.

Sin embrago, el particular en el caso, Sr. COSTA, pidió un reenvío prejudicial según la disposición en el articulo 234. Esto implica que el juez tenía que preguntar al TJCE como debía actuar. La respuesta fue que una ley nacional no podía derogar el derecho comunitario en el ámbito exclusivo de la competencia de la Comunidad Europea. Con la transición de la soberanía hacia el nivel comunitario, el derecho de la CE adquirió la primacía en su propio ámbito. Así se estableció que el juez italiano estaba obligado a aplicar el derecho comunitario, no aplicando la ley nacional posteriormente instituida.

\footnotetext{
TJCE, sentencia del 14 de julio de 1994, Faccini Dori, as. 91/92, Rec. 1994 págs. I-3325, párrafo 26 "Cuando se aplica la ley nacional tiene que hacerlo conforme la posibilidad, a la luz de la palabra de la directiva para que pueda alcanzar el resultado propuesto y pues cumplir con el tercer párafo del articulo 189 TCE (nuevo 249)"

- TJCE, sentencia del 15 de julio de 1964, Costa / ENEL, as. 6/64. Rec. 1964, págs. 1141 y sigtes.
} 


\section{2.d. Resumen}

En resumen, el efecto directo del derecho originario y derivado en colaboración con la teoría de la primacía del derecho comunitario, hace que el particular tenga la posibilidad de apoyarse sobre el derecho comunitario para justificar su demanda en un procedimiento al nivel nacional.

\section{El Sistema de Aplicación de Derecho Comunitario}

Ahora trataremos de dar una idea de cómo se aplica el derecho comunitario. Primero explicamos el mecanismo de control para que no surja una jurisprudencia asimétrica dentro de cada Estado Miembro. Luego examinaremos brevemente dos recursos para los particulares frente al TJCE.

Antes de explicar el mecanismo de control, parece interesante apuntar unos características del sistema judicial comunitario.

El poder judicial no pertenece únicamente al TJCE. Con respecto a la aplicación del derecho comunitario, las jurisdicciones nacionales y el TJCE se encuentran en una situación de cooperación. Según su definición, la jurisprudencia del derecho comunitario está formada por todas las sentencias, bien del TJCE, bien de los tribunales nacionales.

Ello se explica a través del principio de subsidiaridad (artículo $5 \mathrm{CE}$ : Para ser un verdadero derecho, fácil de alcanzar para sus sujetos, importa que sea aplicado en los tribunales de primera instancia en los ordenes nacionales).

\section{a. Reenvío Prejudicial}

El artículo 234 del TCE crea el mecanismo para promover la subsidiaridad y al mismo tiempo vigilar la preservación de las características propias del derecho comunitario. Así para garantizar que tenga el mismo efecto en todos los Estados de la Comunidad. ${ }^{7}$ Artículo 234 dice;

"El Tribunal de Justicia será competente para pronunciarse, con carácter prejudicial:

a) sobre la interpretación del presente Tratado

b) sobre la validez e interpretación de los actos adoptados por las instituciones de la Comunidad y por el BCE 
c) sobre la interpretación de los estatutos de los organismos creados por un acto del Consejo, cuando dichos estatutos así lo prevean

Cuando se plantee una cuestión de esta naturaleza ante los Estados miembros, dicho órgano podrá pedir al Tribunal de Justicia que se pronuncie sobre la misma, si estima necesaria una decisión al respecto para poder emitir su fallo.

Cuando se plante una cuestión de este tipo en un asunto pendiente ante un órgano jurisdiccional, cuyas decisiones no sean susceptibles de ulterior recurso judicial del Derecho interno, dicho órgano estará obligado a someter la cuestión al Tribunal de Justicia."

Lo importante del articulo se presenta en el tercer párrafo. La obligación de proceder al reenvió prejudicial, garantiza a los particulares que el control de la validez o la interpretación de un acto comunitario procederá al TJCE. Así, la interpretación del derecho comunitario no depende finalmente de los jueces internos, sino del TJCE. Lo cual dará una aplicación homogénea del derecho comunitario en el bloque que forma la Comunidad Europea.

Aquel sistema de control ilustra un compromiso entre dos principios fundamentales del derecho comunitario, primacía y subsidiariedad. La subsidiariedad se expresa en cuanto el tribunal nacional tiene la facultad de interpretar el derecho comunitario pero sólo hasta el límite que impone la tercer parte del artículo, o sea en la última instancia judicial nacional sólo al "juez supremo" le compete proceder a la interpretación. Esto ultimo muestra el principio de primacía del derecho comunitario sobre el derecho nacional.

Hasta este punto vimos lo que un particular puede alcanzar en un tribunal nacional. Ahora parece adecuado mencionar dos tipos de recursos que los particulares pueden iniciar directamente frente al TJCE.

Estos recursos son relacionados con el Reenvío Prejudicial. Por tal razón vamos ahora examinar estos recursos para luego ver cómo colaboran los procesos.

\section{b. Recurso de anulación artículo 230 CE y Recurso por omisión, artículo 232}

El TJCE esta encargado del control de la legalidad del derecho comunitario derivado. Eso significa que el TJCE funciona semejante a una corte constitucional con respecto de las normas derivadas. Con respecto al derecho originario, el TJCE nunca va controlar los Tratados, porqué debe su existencia a los Tratado, y no podría declarar ilegal su mismo fundamento. 
La tarea del TJCE es vigilar la jerarquía de las normas del derecho comunitario, y más allá, vigilar los limites de la competencia de las instituciones comunitarias. En este sentido la Corte tiene una función de autoridad sobre las acciones de las otras instituciones comunitarias.

\section{b.i. La capacidad de iniciar un proceso de anulación:}

Primero, es claro que las instituciones con poder judicial (la Comisión y el Consejo) tienen capacidad de impugnar un acto que proviene de otra institución comunitaria. Además, como son los Estados Miembros que son los destinatarios de la mayoría de los actos comunitarios, parece lógico que, los EM pueden iniciar un proceso para llegar a la anulación de un acto que le afecta. Así según el segundo párrafo del artículo, la Comisión, el Consejo y los EM quienes tienen derecho a iniciar tal proceso. Y según el tercer párrafo, con el fin de salvaguardar sus propias prerrogativas, pueden recurrir al tribunal, el Parlamento Europeo y el Banco de la Comunidad Europea.

El artículo 230 dice en el cuarto párrafo: "Toda persona fisica o jurídica podrá interponer, en las mismas condiciones, recurso contra las decisiones de las que sea destinataria y contra las decisiones que, aunque revistan la forma de un reglamento o de una decisión dirigida o otra persona, le afecta directa e individualmente."

El control de la legalidad de los actos derivados normalmente no implica la participación de los ciudadanos. Sin embargo, el tercer párrafo del articulo 230 prevé que en el caso de que un acto le afecte a un particular (en forma de una decisión o un reglamento), puede recurrir al proceso de anulación.

\section{b.ii. La legitimidad activa de los particulares en un proceso de anulación}

Los particulares son considerados "demandantes no privilegiados" porque tienen que justificar su interés para pedir la anulación. La jurisprudencia en el tema, ha sido abundante en cuanto a definir los criterios para la justificación de tal interés. Aunque un particular no es el destinatario directo de una decisión de la Comisión, la situación de los hechos puede permitir una analogía entre el destinatario y las personas que son afectadas por la decisión ${ }^{10 .}$

\footnotetext{
'TJCE, sentencia del 15 de julio de 1963, Plaumann, as. 25/62, p. 199 Rec.1963; TJCE, sentencia del 2 de julio de 1964, Glocoseries, as.1/64, p. 83. Rec. 1964; TJCE, sentencia del 1 de abril de 1965, Sgarlata, as. 40/64, p. 279. Rec. 1965.

toTJCE, sentencia del 1 de julio de 1965, Toepfer, as. 61963j0106, p. 525. Rec. 1965 
Con respecto a los reglamentos que, según sus características inherentes, normalmente son generales. El TJCE ha constatado que cuando se reúnen ciertas condiciones, puedan concernir individualmente a un particular ${ }^{11}$. A contrario sensu una interpretación estricta del sentido literal de un reglamento, la jurisprudencia ha creado un derecho por el cual los particulares pueden recurrir a la anulación de un reglamento.

\section{b.iii Recurso por omisión, artículo 232;}

El recurso por omisión es un control de legalidad, distinto al recurso de la anulación. Sin embargo, son necesariamente complementarias. Este mecanismo está establecido para controlar la falta de acción de alguna de las instituciones, en el caso que hubiera tenido obligación de actuar.

El tercer párrafo del articulo 232 dice;

"Toda persona física o jurídica podrá recurrir en queja al Tribunal de Justicia, en las condiciones señaladas en los párrafos precedentes, por no haberle dirigido una de las instituciones de la Comunidad en acto distinto de una recomendación o de un dictamen."

La jurisprudencia del TJCE ha sido determinante para la interpretación de las exigencias del articulo 230. Semejante al recurso de anulación, el particular puede "impugnar la omisión de actos cuya adopción le podía afectar directa e individualmente, aunque no fuese destinatario de los mismos"12.

\section{c. Las relaciones entre el reenvío prejudicial y recurso de anulación o por omisión}

Resulta que el particular tiene dos maneras de recurrir a un proceso implicando la aplicación del derecho comunitario.

El primer recurso, reenvío prejudicial (art. 234) es un mecanismo de carácter general y es pertinente para avanzar la implementación del derecho comunitario en el orden nacional. El mecanismo obliga al juez nacional de tomar en cuenta el derecho comunitario, cuando esta aplicando la ley nacional.

En el segundo camino posible, recurso de anulación o por omisión (art 230 y 232), los particulares consiguen un papel más predominante respecto a la vigilancia y desarrollo del derecho comunitario. Los autores del Tratado de la CE querían evitar que los particulares pudieran entrometerse en la elaboración del derecho comunitario. De tal razón,

"TJCE, sentencia del 13 de mayo de 1971, International Frut Company,as. 41/70, p. 411. Rec 1971. ${ }^{12}$ TJCE, sentencia del 16 de febrero de 1993, ENU c/ Comisión, as. C107/91, p. 599. Rec. 1993. 
la posibilidad de los particulares a recurrir a la anulación o proceder al recurso por omisión ha sido limitada.

Sin embargo es racional que en cuanto el efecto directo impone obligaciones comunitarias a las personas, estas puedan atacar los actos comunitarios que les imponen estas obligaciones. Diferentemente de un proceso en el orden nacional, este proceso normalmente trata de solucionar un choque entre la jerarquía de dos normas comunitarias. Asi que el TJCE tiene que controlar si las normas se contradicen, y tiene que anular la norma inferior.

\section{c.i la interpretación de los recursos de los arts. 230 y $232 \mathrm{CE}$ en el reenvío prejudicial}

Ahora bien, limitada la posibilidad de recursos de los art. 230 y 232, un particular puede, a través de un reenvio prejudicial (art. 234) en un proceso nacional, conseguir que el TJCE declare la invalidez de una disposición comunitaria. Esta posibilidad está abierta aunque el particular no pueda atacar la disposición actual directamente por vía del artículo $230^{13}$.

Concretamente, en el caso de contradicción entre una norma comunitaria y una norma interna el juez nacional puede preguntar al TJCE no sólo si tiene que aplicar la norma comunitaria sino aún si la norma comunitaria es válida.

Por medio de tal proceso (reenvío prejudicial) el particular no tiene que demostrar que el acto comunitario le afecta individualmente.

Es importante que en tal proceso el efecto de una declaración de invalidez sea más limitado que un juicio de anulación. Invalidez es más ligero como efecto que la anulación. Sin embargo esta forma de procedimiento está abierto a un alcance de actos comunitarios más vasto que el recurso directo de anulación.

En este momento es importante diferenciar entre el proceso de control de legalidad iniciado por un particular frente al TJCE, y en un proceso judicial en el orden interno en cuanto la persona se apoya sobre el derecho derivado comunitario en su argumentación legal.

\section{Resumen}

De los dos ordenes que son abiertos para el particular, en la elaboración

"Commenaire Megret, Droit de la CEE no. 10, La Cour de Justice Les Actes des Institutions, Editions de L' Université de Bruxelles p. 202. TJCE, sentencia del 11 de julio de 1974, Dassonville, as. 8/ 74 Rec 1974 pag. 837. 
del derecho comunitario es el nacional que ha sido promovido.

Normalmente el particular no tiene posibilidad de reclamar la anulación de una ley nacional, sólo que el juez no se la aplica en su caso. Ni el TJCE puede declarar invalido o anular una norma de derecho interno.

En el orden comunitario el particular ha sido atribuido con un derecho a reclamar la anulación de una norma comunitaria.

En resumen podemos decir que tenemos dos niveles de derecho, el nacional en el primer escalón y el comunitario en el que le sigue. El primero se usa como instrumento para el progreso del segundo.

\section{Caso}

A continuación plantearemos un caso hipotético al sólo efecto de mostrar cómo un individuo de la comunidad europea accede a la jurisdicción del TJCE.

Un agricultor inglés cuya industria radica en la cría de ganado para la exportación dentro de la Comunidad Europea realiza un contrato con un supermercado sueco para abastecerlo de carne vacuna por un período de dos años. El contrato establecía que se debían enviar cinco toneladas de carne en diferentes cortes por mes.

El envío y el pago se realizaron exitosamente durante los dos primeros meses. Antes de que el supermercado hubiera recibido la tercera entrega, se dio a conocer mundialmente el escándalo llamado "la vaca loca" y sus terribles efectos en los seres humanos. Como consecuencia de la difusión de la noticia y el desprestigio de la carne vacuna, disminuyó notablemente el consumo.

El gobierno sueco teniendo conocimiento de que gran parte de la carne vacuna consumida en su país provenía de Inglaterra y con el fin de evitar la propagación de la enfermedad decidió intervenir. El Poder Legislativo (riksdagen) dictó una ley conforme la cual las vacas debían llegar vivas a Suecia para poder ser examinadas y, si y sólo si, las autoridades especialmente designadas por el gobierno sueco, específicamente Ministerio de Agricultura y Ganadería (jordbruksdepartementet) determinaban que dichas vacas estaban libres de la enfermedad, se les permitiría a éstas la entrada al país. De lo contrario, serían incineradas en el momento con motivo de erradicar el mal.

Al llegar el cargamento a la frontera sueca, fue rechazado por tratarse de cortes vacunos y no de vacas tal como prescribe la ley sueca recientemente promulgada.

Frente a los hechos comentados, el productor inglés, dadas las particulares ca- 
racteristicas de la carne vacuna, decide iniciar una acción de amparo (interims beslut)

Se trata de una decisión tomada por la aduana sueca (tullen), o sea, un órgano de las autoridades nacionales (tullverket). En caso de apelar tal decisión, el productor inglés deberá presentarse al tribunal de primera instancia de las autoridades publicas (länsrätten). Allí se reciben todos los casos relacionados con las decisiones aduaneras.

El productor inglés apelará la decisión que rechazaba sus productos con los siguientes argumentos: el principio de libre circulación es una norma de derecho originario, se encuentra en el artículo 28 del TCE. Este artículo prohíbe todas las restricciones al comercio entre los Estados Miembros. El derecho originario tiene efecto directo y primacia, por lo tanto el juez nacional tiene la obligación de ignorar la ley sueca y anular la decisión (y no la ley) aduanera.

Dentro de este procedimiento el productor puede reclamar un reenvio prejudicial para que el TJCE pueda esclarecer la situación entre la ley sueca y el principio de libre circulación.

Desde el punto de vista práctico, un reenvío tal puede demorar el proceso hasta dos años, así es un obstáculo real de alcanzar el derecho comunitario.

El juez sueco no puede anular una ley sueca, sólo puede dejarla sin fuerza, y el productor puede seguir exportando a Suecia. ${ }^{14}$

Puede ser que en el caso actual el juez sueco aplique el artículo 30 y dé fuerza a la ley por razón de seguridad de la salud pública.

En tal caso que el productor no gana, o sea, el juez sueco da primacía a la ley nacional, el productor puede hacer una reclamación frente de la Comisión. Sin embargo este es sólo una forma de informar a la Comisión la situación. La Comisión, según el artículo 226, tiene a su discreción el poder de iniciar un proceso de incumplimiento del Tratado contra Suecia. El riesgo es que la Comisión, por razones políticas, deja de iniciar tal proceso.

Aunque el derecho comunitario le da muchos derechos al particular, no le da el derecho a iniciar un recurso de incumplimiento del Tratado. Es lógico, ya que el Tratado es entre Estados y no entre el Estado y el particular.

\section{MERCOSUR: Efecto Directo, Primacía, Efecto Inmediato. ${ }^{15}$}

\section{En esta parte del trabajo trataremos de mostrar la existencia del efecto}

\footnotetext{
"REGERINGSFORORDNINGEN KAPITEL \& $\$$ 17(Reglamento de Gobiemo): "Lag far ef andras eller upphävas annat än genom lag." Una leg no puede ser modifcada o anulada por otra ley. Así un juez no puede tomar la decisión de anular una ley.

2. Para el desarrollo del siguente achipite se utilizó como bibliografia fundamental PEROTT, Alejandro Daniel, "Estructura institucional y Derecho on el Mercosur", Revista de Derecho Internacional y del Mcrcosur, año 6, $N^{\text {zi }}$ 1, febrero, Fdit: La Ley, Buenos Aires, Argentina, 2002 (en prensa).
} 
directo, efecto inmediato y de la primacía en el derecho del MERCOSUR.

Como primer paso debemos recordar brevemente de qué se trata cada uno de estos efectos de los que estamos hablando:

* Efecto Directo: El concepto ha sido elaborado por el Tribunal de Justicia de la Comunidad Europea. Este efecto significa que la norma comunitaria puede ser invocada no solo por los estados, sino también por sus particulares. Aquí podemos mencionar una marcada diferencia con el Derecho Internacional Público donde las normas sólo pueden ser invocadas por los estados y no por los particulares, ya que estos no son sujetos de Derecho Internacional Público. Según la sentencia Van Gend, para que una norma tenga efecto directo debe reunir dos condiciones: 1- que la disposición sea incondicional; 2 -suficientemente precisa.

Deacuerdo con este importante efecto, un ciudadanoespañol puededemandarante un tribunal de su país que secumpla con una norma del tratado constitutivo de la $\mathrm{CE}$.

* Efecto Inmediato: Mediante este efecto, la norma comunitaria una vez sancionada y publicada o notificada, entra en vigencia sin necesidad de un acto de incorporación de parte de los Estados. La norma se incorpora al derecho interno de manera automática.

* Primacía: Este principio de primacía, también elaborado por el Tribunal de Justicia de la comunidad europea ${ }^{16}$, hace prevalecer en caso de conflicto el derecho comunitario sobre el derecho interno de los Estados.

Este principio es absolutamente necesario para conformar un ordenamiento jurídico autónomo del derecho interno e internacional, que se integra en los sistemas jurídicos de los Estados miembros y se impone a sus jurisdicciones.

Pasaremos a ver ahora si encontramos normas del MERCOSUR que contengan alguno de los efectos en cuestión.

Para comenzar a hablar del principio de primacía, es preciso remitirse a la jurisprudencia del TJCE, precisamente en el leading case Costa, donde se resolvió que una norma interna no podía dejar sin efecto a una norma comunitaria. Los fundamentos de la sentencia son interesantísimos ya que sienta las bases o mejor dicho, sigue la labor que había comenzado con el otro leading case: Van Gend.

Establece al derecho comunitario como un ordenamiento autónomo, en donde el tratado constitutivo sería la Constitución. Este derecho no es un derecho internacional público, ni especial, se construye un ordenamiento propio de la comunidad. 
Hasta aquí nada obsta a que esta doctrina sea aplicada al MERCOSUR, ya que también tenemos un tratado constitutivo que es el que se firmó en Asunción en 1991.

Luego el TJCE continua hablando la duración indefinida del tratado, de la capacidad jurídica de la Comunidad y de los poderes o competencias que han sido "delegados" por los Estados. Es una transferencia de atribuciones de los Estados a la Comunidad. Aquí podemos citar el art.19 $\mathrm{TA}^{17}$ y $48 \mathrm{POP}^{18}$ que dan duración indefinida a los respectivos tratados.

En cuanto a la personalidad jurídica, debemos remitirnos al capitulo II del Protocolo Ouro Preto ${ }^{19}$, donde se establece la personalidad jurídica de Derecho internacional para el MERCOSUR.

También al MERCOSUR se le han otorgado competencias y poder de representación, esto conforme al art. 8 inc. 4,14 inc. 7 del POP ${ }^{20 .}$

La sentencia Costa también establece "la primacía del Derecho comunitario está confirmada por el art. 189, a cuyo tenor los Reglamentos tienen fuerza obligatoria y son directamente aplicables en cada Estado miembro; ...esta disposición carecería de alcance si un Estado pudiera unilateralmente destruir sus efectos mediante un acto legislativo oponible a las normas comunitarias." Es decir, si cada Estado cambia las "reglas del juego" cada vez que no le conviene, el sistema comunitario es un caos y sería imposible su aplicación. Esto sucedería si cada ordenamiento dictara normas en contradicción con el Derecho comunitario y las intentara aplicar sobre el tratado, estaría derogando unilateralmente normas comunitarias.

${ }^{17}$ Articulo 19: El presente Tratado tendrá duración indefinida y entrara en vigor 30 dias después de la fecha de depósito del tercer instrumento de ratificacion. Los instrumentos de ratificación setán deposiv tados ante el Gobicno de la Republica del Paraguay que comunicará la fecha de depósito a los gobiernos de los demás Estados Partes. El Gobierno de la Republica del Paraguay notificaráal Gobicmo de cada uno de los demás Estados Partes la fecha de entrada en vigor del presente Tratado. "Artículo 48: El prescnte Protocolo, parte integrante del Tratado de Asunción, tendrá duración indefinida y entratá en vigor 30 dias después de la fecha del depósito del tercer instumento de tatificación. El presente Protocolo y sus instrumentos de ratificación serán depositados ante el Gobienno de la República del Paraguay Articulo 34: El Mercosur tendrá personalidad juridica de Detecho Internacional.

Articulo 35: El Mercosur podrá, en el uso de sus atribuciones, practicar todos los actos necesarios para la realización de sus objetivos, en especial contratar, adquirir o enajenar bienes muebles e inmuebles, comparecer en juicio, conservar fondos y hacer transferencias.

21: Artículo 8: Son funciones y atribuciones del Consejo del Mercado Comtu:

IV - Negociar y firmar acuerdos, en nombre del Mercosur, con terceros paises, grupos de paises y organismos internacionales. Dichas funciones podrân ser delegadas por nandato expreso al Grupo Mercado Comun en las condiciones establecidas en el inciso VII del axtículo XIV;

Artículo 14: Son funciones y atribuciones del Grupo Mercado Comín:

VII - Negociar, con la participación de representantes de todos los Estados Partes, por delegacion expresa del Consejo del Merado Común y dentro de los límites establecidos en mandatos especificos concedidos con esa finalidad, acuerdos en nombre del Mercosur con terceros páses, grapos de países y organismos internacionales. El Grupo Mercado Común, cuando disponga de mandato para tal fin, procedera a la firma de los mencionados acuerdos. El Grupo Mercado Común, cuando sea autorizado por el Consejo del Mercado Común, podrá delegar los referidos poderes a la Comisión de Comercio del Mercosur; 
Tanto Paraguay como Argentina tiene receptado en sus constituciones, la primacía de los tratados sobre el derecho interno. En nuestra ley fundamental se encuentra en los art. 31, 75 inc. 22 y 24; en Paraguay, art. 137, 141, 143, 144 y 145 de la Constitución.

Por otro lado, Brasil y Uruguay no tienen en sus textos constitucionales normas como las de Paraguay y Argentina. Pero la jurisprudencia brasilera ha reconocido la regla de la primacía en varios tribunales federales.

Ahora vamos a pasar a comentar la inserción del efecto directo en el MERCOSUR. Como primera medida para reconocer una norma que goce del efecto directo, debemos constatar que esta se presente precisa e incondicional.

A continuación, citamos algunos artículos del Tratado de Asunción que poseen efecto directo:

1. En el art. $1^{21}$ se establecen la libertad de circulación de bienes, servicios y factores productivos. Esto quiere decir que un particular de un Estado miembro puede reclamar el cumplimiento de esta norma si se le impide o dificulta el comercio en un paso fronterizo con otro país del MERCOSUR, ya sea por medidas arancelarias o no arancelarias que de igual manera están prohibida por el presente artículo.

2. En el art. $4^{22}$ se hace referencia a las condiciones equitativas de comercio -dumping entre otros- y así se trata de proteger la competencia desleal. Por lo tanto, un particular afectado por dumping o subsidios, invocando el art. 4 puede defender su comercio o actividad.

3. El art. $7^{23}$ es otra clara norma de efecto directo ya que regula sobre materia impositiva, tasas $y$ otros

gravámenes.

Por último nos falta hablar del efecto inmediato en el sistema jurídi-

\footnotetext{
${ }^{21}$ Artículo 1: Los Estados Partes deciden constituir un Mercado Común, que deber estar conformado al 31 de diciembre de 1994, el que sc denominará "Mercado Común del Sur" MERCOSUR.

Este Mercado Común implica

-La libre circulación de bienes, servicios y factores productivos entre los países, a través, entre otros, de la eliminación de los derechos aduaneros y restricciones no arancelarias a la circulación de mercaderías y de cualquier otra medida equivalente;

-El establecimiento de un arancel externo común y la adopción de una política comercial común con relación a terceros Estados o agrupaciones de Estados y la coordinación de posiciones en foros económico-comerciales regionales e internacionales;

-La coordinación de políticas macroeconómicas y sectoriales entre los Estados Partes: de comercio exterior, agrícola, industrial, fiscal, monetaria, cambiaria y de capitales, de servicios, aduanera, de transportes y comunicaciones y otras que se acuerden, a fin de asegurar condiciones adecuadas de competencia entre los Estados Partes;

-El compromiso de los Estados Partes de armonizar sus legislaciones en las áreas pertinentes, para lograr el fortalecimiento del proceso de integración.

${ }^{22}$ Artículo 4: En las relaciones con terceros países, los Estados Partes asegurarán condiciones equitativas de comercio. A tal efecto, aplicarán sus legislaciones nacionales para inhibir importaciones cuyos precios estén influenciados por subsidios, dumping o cualquier otra práctica desleal. Paralelamente, los Estados Partes coordinarán sus respectivas políticas nacionales, con el objeto de elaborar normas comunes sobre competencia comercial.

${ }^{23}$ Artículo 7: En materia de impuestos, tasas y otros gravámenes internos, los productos originarios del territorio de un Estado Parte gozarán, en los otros Estados Partes, del mismo tratamiento que se aplique al producto nacional.
} 


\section{co del MERCOSUR.}

Para encaminarnos hacia una respuesta al último efecto en cuestión, debemos recurrir al Protocolo Ouro Preto (POP).

En el Cap. IV, precisamente el art. $40^{24}$, establece el procedimiento mediante el cual la norma MERCOSUR entra en vigencia en cada ordenamiento interno. A simple vista este efecto no tendría cabida dentro de este esquema comunitario, ya que los Estados partes deben incorporarlas mediante actos internos, luego informar a la Secretaria Administrativa del MERCOSUR (SAM) y recién cuando todos lo hayan hecho, la SAM lo comunica a cada Estado y 30 días después las normas entran en vigor simultáneamente en todos los Estados parte. A pesar de esto, la Dec. 23/00 establece que no necesitan incorporación las medidas que estuvieran ya contempladas en el derecho interno y las disposiciones que los estados conjuntamente entiendan que están destinadas a regular el funcionamiento interno del MERCOSUR.

Pero siguiendo con la lectura del POP, nos encontramos con un artículo "salvador" y este es el art. $42^{25}$. Esta disposición se encuentra dentro del capitulo de las fuentes del ordenamiento y establece que las normas son de "carácter obligatorio" y sólo cuando sea necesario deben ser incorporadas a la legislación interna. Aquí es donde encontramos una posible contradicción en los artículos citados ( 40 y 42 ). Por un lado el Protocolo prevee un procedimiento para la incorporación de la norma (negaría el efecto inmediato) y por el otro, tenemos la norma que establece como regla la no incorporación por parte del Estado salvo en los casos que sea necesario. Resta entonces determinar cuando es necesario la internalización de la norma. Pero creemos que esta respuesta no la debe dar cada Estado, sino el propio Derecho MERCOSUR, de lo contrario estaríamos dejando a la libre conveniencia de cada parte cuando la nor-

\footnotetext{
"Artículo 40: Con la frnalidad de garantizar la vigencia simultánea en los Estados partes de las nomas emanadas de los órganos dél Mercosur previstos en el Articulo 2 de este Protocolo, deberá seguirse el siguiente procedimiento:

i) Una vez aprolada la norma los Estados Partes adoptarán las medidas necesarias pam su incorporación al ordenamiento juridico nacional y comunicarán las mismas a la Secretaria Administrativa del Mercosur; ii) Cuando todos los Estados Partes hubieren informado la incorporación a sus respectivos ordenamientos juridicos internos, la Secretaria Administrativa del Mercosur comunicará el hecho a cada Estado Parte;

iii) Las normas entrarán en vigor simultáneamente en los Estados Partes 30 dias después de la fecha de comunicación efectuada por la Secretaría Administrativa del Mercosur, en los términos del literal anterior. Con ese objetivo, los Estados Partes, dentro del plazo mencionado, darán publicidad del incicio de la vigencia de las referidas normas por intermedio de sus respectivos darios oficiales.

"Articulo 42: Las normas emanadas de los órganos del Mercosur previstos en el Artículo 2 de este Protocolo tendrản carácter obligatorio $y$, cuando sea necesario, deberán ser incorporadas a los ordenamientos jurídi$\cos$ nacionales mediante los procedimtentos previstos por la legislacion de carta pais.
} 
ma debe ser incorporada por acto interno.

Teniendo esto en cuenta, podemos concluir que la norma comunitaria va a necesitar la internalización en los casos en que la propia disposición lo requiera o esta no pueda operar por sí sola, es decir directivas que deberán ser desarrolladas por cada Estado miembro. ${ }^{26}$ Acorde con esta interpretación, el art. 40 estaría destinado para aquellas normas que el sistema comunitario requiere la internalización.

Es oportuno en este momento hablar brevemente de los laudos arbitrales para conocer la "jurisprudencia" sobre los tres efectos en estudio. El TAHM ${ }^{27}$ es, por el momento, el único sistema de resolución de controversias.

El primer laudo ${ }^{28}$ es muy alentador. Se enfrentaban Argentina y Brasil y la controversia versaba sobre las licencias para importar que imponía Brasil. El laudo fue favorable para Argentina en el derecho, pero no en los hechos. Veamos qué principios se afirmaron en este fallo arbitral:

" Principio de primacía: "son incompatibles las medidas unilaterales de los Estados Partes en las materias en las que la normativa requiere procedimientos multilaterales" (considerando

* Efecto inmediato: "disposiciones que son por sí mismas ejecutables, imponiendo obligaciones concretas a las Partes, sin necesidad de nuevos actos jurídicos por los Estados" (considerando 64); "los cinco Anexos al TA" contienen obligaciones concretas y auto ejecutables" (considerando 66)

Pero no todos los laudos fueron tan pro integración como el primero, ya que el segundo ${ }^{30}$ desconoció el efecto directo e inmediato a la Dec. 10/94.

En el tercer laudo ${ }^{31}$ se trató todo lo relacionado con las cláusulas de salvaguardia. Y de este laudo surgen los siguientes principios:

* Principio de primacía: Aquí se dijo que el MERCOSUR excluye las medidas nacionales unilaterales que contravengan el sistema implantado por el TA.

"Efecto directo: "La necesidad de certeza jurídica y previsión no se limita al interés de los Estados miembros del MERCOSUR sino que incluye a toda la comunidad relacionada con negocios que tienen una expectativa legítima

\footnotetext{
2. Por ejemplo un mandato comunitario para que los Estados regulen lo relativo a la contaminación ambiental mediante controles y restricciones a los caños de excape de los automóvies, camiones, moros, etc. 27. Tribunal ad-hoc del Mercosur

24 TAlIM, as. 1/99, RDM, N 4, año 3, agosto, 1999, pags. 257-278.

2) Tratado de Asunción.

35. TAHM, asunto 2/99, Subsicios a la producción y exportación de cane de cerćo, 27/IX/99. Publicado en LL del 10/X11/99, pág. 2-3.

31 TAHM, asunto 1/00, Aplicación de Medidas de Salvaguardia sobre productos Textiles (Res. 861/99) del Ministerio de Economía y Obras y Servicios Públicos (MEOySP), 10/1II/00. Publicado en RDM Na 3 , año 4 , junio, 2000, págs. 138-164.

La Decisión fue objeto de una solicitud de aclaratoria, interpuesta por la parte demandada, y resuelta por unanimidad, por ol Tribunal el $7 / \mathrm{N} / 00$.
} 
sobre la existencia actual de un libre comercio" (considerando III.H.3)

Con estas decisiones arbitrales que hemos citado, queda plasmado el esfuerzo de algunos árbitros por tratar de dar al ordenamiento jurídico comunitario los efectos indispensables para lograr un Mercado Común. Tarea que se torna muy difícil al no tener un órgano jurisdiccional permanente como en otros sistemas comunitarios(TJCE, TJCA, CCJ)

A modo de conclusión y cierre del presente acápite, creemos necesario remarcar que la existencia de los tres efectos en análisis, no dependen de un ordenamiento nacional o del derecho internacional, sino que va a derivarse del propio derecho comunitario. Este derecho lo debemos concebir como autónomo y por supuesto con características propias, limitando competencias de los Estados. De no considerar al MERCOSUR de esta manera será muy difícil conseguir la integración regional definitiva.

\section{Ius Inter Iura: la relación entre el derecho argentino y el ordenamiento jurídico del MERCOSUR.}

La relación entre el ordenamiento jurídico argentino con los Tratados Internacionales ha sido tema de debate tanto en la doctrina como en la jurisprudencia nacional. Siguiendo a BOGGIANO 32 "el derecho internacional continúa en los derechos internos. Los derechos internos continúan en el derecho internacional. Ni éste ni los derechos internos son vistos aquí tan solo como un conjunto de normas sino como un solo y único sistema de procesos de decisiones autorizadas. En este proceso se dan los continuos."

El Tratado de Asunción, sus protocolos, incluido el de Ouro Preto que es parte integrante del Tratado de Asunción y los instrumentos adicionales configuran el derecho originario o constitucional del MERCOSUR. Tanto el Tratado de Asunción como aquellos que lo modifican son tratados internacionales regidos por el derecho internacional ${ }^{33} \mathrm{y}$ la Convención de Viena sobre Derecho de los Tratados. En la República Argentina, conforme el art. 31 de la Constitución Nacional: "Esta Constitución, las leyes de la Nación que en su consecuencia se dicten por el Congreso y los tratados

\footnotetext{
32 Boggiano, A. “Teoría del Derecho Internacional. Las relaciones entre los ordenamientos jurídicos”, La Ley, Buenos Aires, 1996, pág. 1

3.3 Sien es correcto que los tratados de integración se rigen por el derecho internacional, es preciso distinguirlos de los tratados internacionales ordinarios ya que los tratados de integración crean un ordenamiento jurídico propio. Y tienen las siguientes características: tienden a la constitución de una federación de duración indefinida, con instituciones propias, personalidad jurídica, con representación internacional de los Estados miembros, y a la cual éstos le ceden ciertas competencias o bien limitan su soberanía a favor del proceso de integración.
} 
con las potencias extranjeras son la ley suprema de la Nación (...)"

Hasta la reforma constitucional de 1994 existían en la doctrina nacional dos posturas: la monista, "su punto de vista postula la unidad del ordenamiento jurídico, donde la primacía radica en el orden internacional" ${ }^{34}$ de la cual KELSEN ha sido defensor. Y, por otro lado, la teoría dualista "defendía la igualdad jerárquica entre las disposiciones de los tratados y las leyes nacionales (con lo que una ley posterior podía derogar un tratado anterior). ${ }^{35}$ "

La CSIN en 1949, resolvió en el caso "Merck Química"36 lo siguiente: Si bien los Tratados están en un nivel inferior a la CN esto será así durante los tiempos de paz, ya que en tiempos de guerra esta relación se invertirá, sentando la siguiente doctrina: "(...) que en tanto se trate de mantener la paz o afianzar el comercio con las potencias extranjeras, la República se conduce dentro de las orientaciones de la teoría 'dualista'. Pero cuando se penetra en el terreno de la guerra en causa propia -eventualidad no incluida y extraña por tanto a las reglas del art.27- la cuestión se aparta de aquellos principios generales y coloca a la República y a su gobierno político, en el trance de cumplir los tratados internacionales con todo el rigorismo de que puedan estar animados". Según COLAUTTI ${ }^{37}$, la corte "apuntó a una distinción entre dualismo en tiempo de paz y un supuesto monismo en tiempo de guerra, donde como ya hemos visto se postuló la supremacía de los tratados inclusive frente a los derechos y garantías constitucionales."

La adhesión de nuestro país a la Convención de Viena sobre el Derecho de los Tratados en el año 1980, la cual en su art.27 sostiene que: "una parte no podrá invocar las disposiciones de su derecho interno como justificación del incumplimiento de un tratado" y, de la cual parte la interpretación del juez BOGGIANO en su voto en el fallo "Cafés La Virginia", según la cual se le "confiere primacía al derecho internacional convencional sobre el derecho interno". Junto con la vuelta a la democracia y la promulgación del Pacto de San José de Costa Rica en el año 1984, por el cual se habilita a los individuos a plantear el incumplimiento de las obligaciones asumidas por el Estado ante la Comisión Interamericana de Derechos Humanos quien haciendo suyo el caso puede llevarlo ante la Corte Interamericana

\footnotetext{
"H Colautti, C. E. "Los Tratados Internacionales y la Constitución Nacional", La Ley, Buenos Aires, 1999, pág. 116. ${ }^{35}$ Freeland Lopez Lecube, A. "Manual de Derecho Comunitario: analtsis comparativo de la Unión Europea y el Mercosur", Editorial Ábaco, Buenos Aíres, 1996, pág 268.

Fis Fallos 211:162

${ }^{17}$ Colautti, C. E., "Los Tratados Intemacionales y la Constitución Nacional", La Ley, Buenos Aires, 1999, pagr 115.
} 
de Derechos Humanos donde el Estado puede ser condenado.

Las circunstancias mencionadas constituyeron el marco jurídico y político en el cual la CSJN falló en el caso "Ekmekdjian c/Neustad" 38 sobre el derecho a réplica, el cual estaba contemplado en la Convención Interamericana y no así en la $\mathrm{CN}$. $\mathrm{Y}$, a su vez resolvió que las normas contenidas en los tratados son superiores a la $\mathrm{CN}$, pero tienen la particularidad de ser programáticas, esto es, requieren de normas que las pongan en ejecución. La Corte Interamericana resolvió que no son normas programáticas.

Luego, en el caso "Ekmekdjian c/Sofovich"39 la CSJN establece que los Tratados Internacionales se aplican por sobre todas las disposiciones de derecho interno. Dado que es un principio de derecho internacional que un estado no puede invocar su derecho interno como excusa de una violación del derecho internacional, la CSIN decidió que la eventual responsabilidad internacional del Estado argentino por el incumplimiento de una obligación convencional no es ajena a la competencia de la Corte en cuanto pueda prevenirla ${ }^{40}$. Así en el considerando $n^{\circ} 20$ del fallo expresa: "Que en el mismo orden de ideas, debe tenerse presente que cuando la Nación ratifica un tratado que firmó con otro Estado, se obliga internacionalmente a que sus órganos administrativos y jurisdiccionales lo apliquen a los supuestos que ese tratado contemple (...) Una norma es operativa cuando está dirigida a una situación de la realidad en la que puede operar inmediatamente, sin necesidad de instituciones que deba establecer el Congreso (...)" La importancia de la aplicación directa reconocida en el fallo citado, radica en conferir a los particulares el derecho propio de hacer valer las normas comunitarias ante los jueces nacionales que tienen la obligación de aplicarlas en los casos sometidos a su jurisdicción interna e internacional. Y así, la tutela directa por los particulares de los derechos que les confiere el derecho comunitario constituye desde ya un control preventivo eficaz.

De aquí también se deduce que la profundización del derecho del MERCOSUR llega hasta la necesaria aplicación de sus normas por los jueces nacionales ${ }^{41}$. Tal es el caso de la Cámara Nacional del Trabajo, Sala

\footnotetext{
LL, 1989 C, 18

$34 \mathrm{LL}, 1992 \mathrm{C}, 540$

46 Boggiano, A. "Derecho Internacional. AD 2000. En la Jurisprudencia de la Corte Suprema de Justicia de la Nación", Ed. La Ley, Buenos Aires, 2000. págs. 669-670

"1 idem anterior. pâg. 672
} 
VI que en reiteradas sentencias se ha remitido a la legislación del MERCOSUR. Por ejemplo en el fallo "Pérez Saravia, Alejandra c/Máxima S.A. A.F.J.P"42 donde se resuelve aplicando: la Declaración Universal de Derechos Humanos, el Pacto Internacional de Derechos Económicos, Sociales, y Culturales, el Pacto Internacional de Derechos Civiles y Políticos, el Pacto de San José de Costa Rica. Todos ellos con jerarquía constitucional otorgada por el art.75 inc.22. Y la Declaración Sociolaboral del MERCOSUR que por su derivación del Tratado de Asunción goza de superioridad a las leyes argentinas.

En el año 1994 es reformada la CN, y en lo referente a las relaciones entre el derecho interno y el derecho internacional se resuelve en el art.75 inc. 22 y 24 . Dicha incorporación se superpone a los arts. 27 y 31 de la CN que no han sido reformados. El inc. 22 establece que los Tratados y concordatos tienen jerarquía superior a las leyes, mientras que aquellos que están expresamente enumerados por la CN tienen jerarquía constitucional, y cualquier otro Tratado sobre Derechos Humanos deberá contar además de la aprobación del Congreso, con el voto favorable de las terceras partes de la totalidad de cada Cámara para gozar de jerarquía constitucional. La doctrina se encuentra dividida en cuanto a la interpretación de este inciso: Por un lado SAGUÉS ${ }^{43}$ sostiene que los Tratados incluso los enumerados no forman parte de la CN pero que valen como ella, por otro lado BIDART CAMPOS" afirma que "las declaraciones y los tratados sobre derechos humanos a los que el inciso 22 reconoce jerarquía constitucional gozan de ella sin estar incorporados a la Constitución y fuera de su texto integran, el llamado bloque de constitucionalidad federal." Y agrega: "la Constitución no ha cedido su cúspide a los instrumentos señalados en el inc.22, pero los ha colocado en ella, aunque sin hacerlos formar parte de su texto." Mientras que, EKMEKDJIAN sostiene que "los constituyentes de 1994 incorporaron al texto constitucional una lista de ocho tratados, dos declaraciones y un protocolo facultativo humanitarios (...) los tratados mencionados en el segundo párrafo del inc. 22 forman parte del texto constitucional, de la misma forma que cualquiera de sus otras partes."

Finalmente la CSJN resolvió en el caso "Monjes c/UBA" en cuanto a los Tratados expresamente enumerados en la CN que "la constitucionalidad de los Tratados expresamente enumerados en el art. 75 inc. 22 párrafo $2^{\circ}$ no podrá ser cuestionada con base en la misma CN. El juicio de

"Saguts, N. P., "Los Tratados Internacionales en la Reforma Constitucional Argentina de 1994", LL 1994E, 1036.

* Bidart Campos, G. "Tratado Elemental de Derecho Constitucional Argentino: la reforma constituci. onal de 1994". Ediar. Bs. As. 1995. T" VI, pág. 555. 
constitucionalidad de esos Tratados fue efectuado por el constituyente."

El inc. 24 se refiere específicamente a los Tratados de Integración y sostiene que las normas dictadas en su consecuencia tienen jerarquía superior a las leyes. La doctrina ha interpretado este inciso en el sentido de que "cualquier ley o norma de derecho interno que se oponga a una comunitaria debe recibir, por lo menos, la misma sanción que en Europa, es decir la no aplicación por el juzgador en beneficio de la regla comunitaria ${ }^{45}$ "

La CSIN falló en el caso "Fibraca c/Comisión Mixta Salto Grande" 46 que las resoluciones de un órgano supraestatal se aplican por sobre las normas de derecho interno. Así también lo ha entendido la doctrina al afirmar: "Las normas de derecho derivado del MERCOSUR tienen aplicabilidad inmediata y efectos directos, en tanto contengan un mandato claro y preciso que no esté sometido a condición. Las normas obligatorias dictadas por los órganos del MERCOSUR prevalecen sobre la legislación interna."

En síntesis, la pirámide jurídica ha quedado actualmente diagramada en la siguiente forma: en el vértice la CN y los Tratados de Derechos Humanos enumerados (en virtud del inc.22 p.2\%), le seguirán los Tratados de Derechos Humanos no enumerados (inc. 22 p. $3^{\circ}$ ), luego el resto de los Tratado internacionales incluidos los de integración (inc.24), más abajo las normas superiores a las leyes (tal como se establece en el caso "Fibraca" para las resoluciones de la Comisión Mixta de Salto Grande), y finalmente las leyes.

En virtud de lo expuesto podemos concluir que el Tratado de Asunción que es el elemento constitutivo del MERCOSUR tiene una jerarquía superior a las leyes pero infraconstitucional. Por lo tanto, ninguna ley interna puede estar en contradicción ni con el Tratado de Asunción ni con el derecho derivado del MERCOSUR.

\section{Caso}

Plantearemos ahora el mismo caso hipotético que utilizáramos para la Comunidad Europea, pero visto desde el MERCOSUR. Ahora entre un productor de pollos brasileño a quien se le impide la entrada a la Argentina basándose en una ley interna cuyo objeto es controlar que los pollos no tengan hormonas agregadas.

El productor de pollos es proveedor de una cadena de supermercados en la Rep. Argentina con quien ha firmado un contrato por dos años, mediante el 
cual se comprometía a entregar mensualmente cinco toneladas de pollo trozado. Una vez en la aduana argentina, el cargamento es detenido invocando la ley anteriormente citada. Dada la circunstancia, el proveedor decide presentar una medida autosatisfactiva ${ }^{47}$ ante el juzgado federal de Misiones, y además, ante la Sección Nacional de la Comisión de Comercio de MERCOSUR de Brasil para que presente el reclamo ante la Comisión de Comercio del MERCOSUR (conforme art.21 POP).

A nuestro entender, el proveedor obtendría mejores resultados ${ }^{48}$ utilizando la vía de la medida autosatisfactiva. De esta manera, ante un juez nacional que está obligado a aplicar las normas comunitarias ${ }^{4 \%}$ el particular vería resuelto su conflicto con mayor celeridad y con la misma efectividad que si hubiese emprendido el camino de la denuncia ante la Sección Nacional correspondiente. Ya que, debido al procedimiento vigente en el POP; es la Sección Nacional quien debe decidir con total discrecionalidad si la denuncia se presenta o no ante la Comisión de Comercio del MERCOSUR. En este caso pueden entrar en juego intereses

\footnotetext{
Conforme $\mathrm{d}$ fallo del juzgado Federal de Concepción del Uruguay (Entre Ríos), autos "F.E.P.S.A. y otros s/medida catutelar, expte. No 774/99": "Las medidas autosatisfactivas o de satisfacción inmediata no tienen apoyatura furidica, éstas son una creación pretoriana. (...) "lo que requieren y necesitan los actores es una tutela urgente que se obtiene a través de una tutela urgente satisfactiva autonoma." Este remedio procesal. es autónomo ya que no requiere y no es accesoria de un proceso principal como todas las medidas cautelares. Según el fallo citado, éstas medidas proceden cuando "se trata de una urgencia impostergable en la que el factor tiempo y la prontimd aparecen cono perentorios; existe una fuert verosimilitud sobre los hechos, con grado de certidumbre acreditada o sumariamente comprobada; la superposición o coincidencia entre el objeto de la pretensión cautelar con la pretensión sustancial do modo tal que su acogimiento consuma el interés juridico (procesal y sustancial) del peticionante." Las medidas autosatisfactivas son necesarias para asegurar ol derecho y que este no se tome ilusorio al momento de la sentencia definitiva. Por lo tanto, es una "tutela judicial procesal cfectiva para remediar, componer, o prexenir una situacion jurdica subjetiva particularmente amenazada y cuya reparación requiere urgencia en la implementación" (Abraham, Luis Vargas: "Medidas..." pág. 121).

"Según PEROTTI, uno de los principales cuestionamientos del sector privado es acerca de la importancia que tiene el reconocimiento, por un órgano jurisdiccional, del principio de la libre Circulación de Mercancias, frente a las continuas restricciones que se imponen en las fronteras a las exportaciones de productos procedentes del Mercosur. A este interrogante, el autor responde: "El valor exacto de este principio es que juridicamente, desde el 1 " de enero de 2000 , están prohibidas por el T.A. y normas concordantes, todas las restricciones arancelarias y no arancelarias, salvo, para estas últimas, cuando sean fundadas en el artículo 50 del Tratado de ALADI. (...) En otras palabras, el reconocimiento en cabeza de los particulares que comercian en el interiot del bloque de un derecho a poder exigir la libre circulación de nuercancias, no impide que, de hecho, los Estados miembros violen tal prerrogativa. Ahorn bien, lo que se garantiza es que tal infracción es perfectamente denunciable y puede dar lugar al incio del sistema de solución de controversias." Si bien el sistema de solución de controversias del Mercosur es deficicnte, esto no significa que el principio de Libre Circulacion de Mercancias no esté vigente ni deba ser cumplido por los Estados miembros. PEROTTI, Alejandro D., "La experiencia argentima en la solución de controversias en el Mercosir", en Jornadas Sistema de Solucion de Controversias on el Mercosur, copia mimeográfica suministrada por el autor con attorización para su cita. Montevideo, Uruguay, 29 de novienabre de 2001. Instituto Industrial de Estudios Superiores Cámara de Industrias de Uruguay (CIU).

19. ver pto. IIIIIB de este trabajo.
} 
del Estado, que no necesariamente se condicen con los del particular.

El 18/02/2002 en la última Cumbre Presidencial se firmó el Protocolo de Olivos, según el cual la discrecionalidad de la Sección Nacional es menor. Dado que es el particular quien debe, en su propio beneficio, demostrar de forma contundente que existe un riesgo o amenaza de daño ${ }^{50}$. Al mismo tiempo, como expresara PEROTTI" : "Respecto de los reclamos de los particulares, la estructura vigente se mantiene, excepto que ahora, una vez que los mismos son admitidos por la sección nacional, el Grupo Mercado Común deberá decidir por consenso (ausencia de voto negativo) para rechazarlos."

Si bien la firma del mencionado protocolo demuestra un avance para el afianzamiento del MERCOSUR, todavía "la escasa posibilidad de acceso directo de los particulares, al contrario de lo que ocurre en Europa o en la zona andina, alienta el recurso a la vía judicial interna (...)”52

\section{Conclusion}

Una vez finalizada nuestra investigación, estamos en condiciones de afirmar que el Mercado Común del Sur (MERCOSUR) tiene capacidad de desarrollar los elementos propios de un sistema de integración subregional. A tal efecto, es esencial la existencia de un tribunal permanente y sobre todo de un fuerte compromiso con la integración por parte de los jueces nacionales, que son en definitiva los jueces comunitarios. Ellos son quienes deben velar por la aplicación y el cumplimiento de la normativa del MERCOSUR.

Tal como se ha podido demostrar a través de los casos hipotéticos planteados ut supra, al particular situado en la CE, le resultó mas sencillo y menos oneroso resolver su conflicto ante los órganos comunitarios; que, a quien se encontraba en el ámbito del MERCOSUR y tuvo que preferir recurrir al juez nacional para obtener una solución.

Creemos firmemente que la integración de los países, tanto a nivel económico, político y jurídico, constituye la herramienta fundamental para competir en un mercado globalizado a nivel mundial. Por ello, consideramos que el MERCOSUR es para la Argentina un buen camino para encontrar la salida a muchas de sus crisis.

\footnotetext{
${ }^{50}$ ver Protocolo de Olivos art. 40 inc. 2: "Los particulares deberán aportar elementos que permitan determinar la verosimilitud de la violación y la existencia o amenaza de un perjuicio, para que el reclamo sea admitido por la Sección Nacional y para que sea evaluado por el Grupo Mercado Común y por el grupo de expertos, si se lo convoca."

${ }_{51}$ Perotti, A. D., "Qué significó el Protocolo de Olivos", en diario "La Nación", suplemento "Comercio Exterior" del 26 de febrero de 2002, pág. 3.

52 Pertotti, A. D., "Qué significó..." obra citada. 


\section{BIBLIOGRAFIA}

BIDART CAMPOS, G. "Tratado Elemental de Derecho Constitucional Argentino: la reforma constitucional de 1994”,. Ediar. Bs. As. 1995. T VI. BOGGIANO, A. "Derecho Internacional. AD 2000. En la Jurisprudencia de la Corte Suprema de Justicia de la Nación”, Ed. La Ley, Buenos Aires, 2000. BOGGIANO, A. "Teoría del Derecho Internacional. Las relaciones entre los ordenamientos jurídicos", La Ley, Buenos Aires, 1996, pág. 1

COLAUTTI, C. E. "Los Tratados Internacionales y la Constitución Nacional", La Ley, Buenos Aires, 1999.

COMMENAIRE MEGRET, Droit de la CEE no. 10, La Cour de Justice Les Actes des Institutions, Editions de L' Université de Bruxelles p. 202. TJCE, sentencia del 11 de julio de 1974, Dassonville, as. 8/74 Rec. 1974.

FREELAND LÓPEZ LECUBE, A. "Manual de Derecho Comunitario: análisis comparativo de la Unión Europea y el Mercosur", Editorial Ábaco, Buenos Aires, 1996.

LAGRANGE, M., "La interpretación unitaria del Derecho de las Comunidades Europeas. Aspecto de la Acción Prejudicial", Revista "Derecho de Integración" N³, INTAL, Buenos Aires, 1968.

PEROTTI, Alejandro D., "La experiencia argentina en la solución de controversias en el Mercosur", en Jornadas Sistema de Solución de Controversias en el Mercosur, copia mimeográfica suministrada por el autor con autorización para su cita. Montevideo, Uruguay, 29 de noviembre de 2001. Instituto Industrial de Estudios Superiores - Cámara de Industrias de Uruguay (CIU).

PEROTTI, Alejandro Daniel, "Estructura institucional y Derecho en el Mercosur", Revista de Derecho Internacional y del Mercosur, año $6, \mathrm{~N}^{ \pm} 1$, febrero, Edit: La Ley, Buenos Aires, Argentina, 2002 (en prensa).

SAGÜES, N. P., "Los Tratados Internacionales en la Reforma Constitucional Argentina de 1994", LL 1994-E, 1036.

TAHM, as. 1/99, RDM, № 4, año 3, agosto, 1999.

TAHM, asunto 1/00, Aplicación de Medidas de Salvaguardia sobre productos Textiles (Res. 861/99) del Ministerio de Economía y Obras y Servicios Públicos (MEOySP), 10/TII/00. Publicado en RDM Nª 3, año 4, junio, 2000.

TAHM, asunto $2 / 99$, Subsidios a la producción y exportación de carne de cerdo, 27/LX/99. Publicado en LL del 10/XII/99.

TJCE, sentencia del 15 de julio de 1964, Costa c/ ENEL, as. 6/64. Rec. 1964. TJCE, sentencia del 1 de julio de 1965, Toepfer, as. 61963j0106, p. 525. Rec. 1965

TJCE, sentencia del 12 de julio de 1990, Foster, as. C-188/89, Rec. 1990. TJCE, sentencia del 13 de mayo de 1971, International Fruit Company,as. 41/70, p. 411. Rec. 1971.

TJCE, sentencia del 14 de julio de 1994, Faccini Dori, as. 91/92, Rec. 1994. 
TJCE, sentencia del 15 de julio de 1963, Plaumann, as. 25/62, p. 199 Rec.1963; TJCE, sentencia del 2 de julio de 1964, Glocoseries, as.1/64, p. 83. Rec. 1964; TJCE, sentencia del 1 de abril de 1965, Sgarlata, as. 40/64, p. 279. Rec. 1965. TJCE, sentencia del 16 de febrero de 1993, ENU c/ Comisión, as. C107/91, p. 599. Rec. 1993.

TJCE, sentencia del 4 de diciembre de 1974, Van Duyn, as. 41/74, Rec. 1974. T.JCE, sentencia del 5 de febrero de 1963, Van Gend en Loos, as. 26/62, Rec. 1963.

Abreviaturas

as: asunto/sentencia del TJCE

BCE: Banco de la Comunidad Europea

CCJ: Corte Centroamericana de Justicia

CE: Comunidad Europea

$\mathrm{CN}$ : Constitución nacional

CSIN: Corte Suprema de Justicia de la Nación

EM: Estado miembro

LL: Revista La Ley

POP: Protocolo de Ouro Preto

Rec: Recueil de la Jurisprudence de la Cour de Justice des Communautés Européennes (Recopilación de Jurisprudencia del Tribunal de Justicia de la Comunidad Europea)

SAM: Secretaria Administrativa del MERCOSUR

TAHM: Tribunal ad-hoc del MERCOSUR

TJCE: Tribunal de Justicia de la Comunidad Europea

T.JCA: Tribunal de Justicia de la Comunidad Andina

TA: Tratado de Asunción 